\title{
Effect of Perch Height and Position on the Usage in Enriched Colony Housing Systems for Laying Hens
}

\author{
Helen Louton ${ }^{1 *}$, Elke Rauch ${ }^{1}$, Sven Reese ${ }^{2}$, Michael Erhard ${ }^{1}$ and Shana Bergmann ${ }^{1}$ \\ ${ }^{1}$ Department of Veterinary Sciences, Chair of Animal Welfare, Ethology, Animal Hygiene and Animal Husbandry, Faculty of Veterinary Medicine, LMU Munich, \\ Veterinaerstraße 13/R, 80539 Munich, Germany \\ ${ }^{2}$ Department of Veterinary Sciences, Chair of Anatomy, Histology and Embryology, Faculty of Veterinary Medicine, LMU Munich, Veterinaerstraße 13, 80539 Munich, \\ Germany
}

\begin{abstract}
In order to determine the utility of different perches in enriched colony housing systems for laying hens, the use of perches and an effect of the type and location in the system was examined in this behavioral study. Laying hens of the line Lohmann Selected Leghorn were housed in four different enriched colony housing systems which differed particularly in the alignment and arrangement of the functional areas. For analysis, perches were grouped into three types: low, low underneath the drinking trough and high. To evaluate the use of the perch types, video recordings were taken for 48 hours during three observation periods. These recordings were analyzed hourly at daytime and twice at nighttime. Through scan sampling, the overall number of hens using the perches and the fraction of hens per meter on a specific perch type were assessed. At nighttime, an average $62 \%$ of the laying hens used the perches. On average, $24 \%$ of the laying hens used the perches at daytime, with no significant difference between the different systems. Low perches that were not installed underneath the drinking trough were less commonly used than high perches. However, the hens used low perches that were positioned underneath the drinking trough more than other perch types during the day. At nighttime, high perches were used frequently and, depending on the system, more than the low perches. It should be considered that the hens used the low perches underneath the drinking trough during the day not to rest but rather to have better access to the drinking trough. It can be recommended that a sufficient number of high perches should be offered, so that all hens have access to these obviously preferred perches. If perches are installed underneath the drinking trough, it should be considered if additional perch space should be offered.
\end{abstract}

Keywords: Layers; Laying hens; Enriched cage; Perch

\section{Introduction}

The enriched colony housing system for laying hens was introduced in 2006 as an alternative to the conventional cage, which was prohibited in Germany as of January $1^{\text {st }}, 2010$. In the year 2010, when the pullets of the presented study hatched, $18.2 \%$ of the laying hens in Germany were housed in an enriched colony housing system [1]. The German "Order on the Protection of Animals and the Keeping of Production Animals" [2] was amended and published on August $22^{\text {nd }}, 2006$ and last changed on February $5^{\text {th }}, 2014$. Due to procedural errors, the German federal constitutional court (BVerfG) declared in October 2010 that $\$ 13 \mathrm{~b}$ of this German order, which regulates the keeping of laying hens in enriched colony housing systems, was unconstitutional [3]. It was therefore legitimate to execute the $\$ 13 \mathrm{~b}$ until March $31^{\text {st }}, 2012$ as a transitional period. Since then, the respective district veterinary offices must evaluate these housing systems during regular animal welfare inspections to assure that the following rules are observed:

Each laying hen must have a minimum absolute usable area of $800 \mathrm{~cm}^{2}$ in the enriched colony housing system. Additionally, for 10 hens a litter area of at least $900 \mathrm{~cm}^{2}$, as well as a nest of at least $900 \mathrm{~cm}^{2}$ and a perch space of $15 \mathrm{~cm}$ per hen must be supplied additionally. At least two perches at different heights in the housing system must be installed for one group, so that an undisturbed rest is possible for all hens at the same time. In order to determine the utility of these necessary perch types, the use of three perch types (low, low underneath the drinking trough and high) and an effect of the location of the perch in the enriched colony housing system was examined in this comparative behavioral study.

Studies have shown that caged laying hens use perches and that perches allow hens to show species-specific resting behavior and increase the well-being of laying hens [4,5]. Many factors are known to influence the use of perches in housing systems by laying hens, with the characteristics of the perch itself such as the diameter and shape [6,7], the material $[8,9]$ and the height being crucial $[10,11]$. However, genetic differences between the hens also may influence the use of different perches [12]. Furthermore, the size of the flocks was shown to influence the choice of different perch heights [13]. In studies examining the acceptance and use of perches in furnished cage systems at daytime, authors reported that hens spent about 25 to $47 \%$ of the daytime on perches $[4,14,15]$. Rönchen et al. [16] observed 10 to $24 \%$ of laying hens on perches in several trials in studies with laying hens in furnished cages, small group systems and modified small group systems. Telle [17] and Hergt [18] recorded 10 to $16 \%$ on perches at daytime in the same housing systems as used in this study. In cagefree housing systems, higher uses of perches are reported during the day by Carmichael et al. [19], with $47 \%$ of the laying hens perching in an aviary system. Duncan et al. [4] observed that the placement of the

*Corresponding author: Helen Louton, Department of Veterinary Sciences, Chair of Animal Welfare, Ethology, Animal Hygiene and Animal Husbandry, Faculty of Veterinary Medicine, LMU Munich, Veterinaerstrasse 13, 80539 Munich, Germany, Tel: 004989218078304; E-mail: h.louton@Imu.de

Received May 02, 2016; Accepted May 26, 2016; Published May 31, 2016

Citation: Louton H, Rauch E, Reese S, Erhard M, Bergmann S (2016) Effect of Perch Height and Position on the Usage in Enriched Colony Housing Systems for Laying Hens. J Vet Sci Technol 7: 339. doi:10.4172/2157-7579.1000339

Copyright: ( 92016 Louton $\mathrm{H}$, et al. This is an open-access article distributed under the terms of the Creative Commons Attribution License, which permits unrestricted use, distribution, and reproduction in any medium, provided the original author and source are credited. 
perch (e.g., near the drinking or food trough) in the system strongly influenced the use. At night time authors observed 81 to $99 \%$ of the laying hens on perches in enriched cage systems $[14,15,20]$. In aviary systems, Plattner [21] found a very high variety in the use of perches by laying hens during the night, ranging from 17 to $100 \%$ of the hens on a perch, depending on the farm.

Studies on perching behavior and the prevalence of hens on different perches in enriched colony housing systems according to the German legislation are rare. In this study, the perching behavior of laying hens in four different enriched colony housing systems was observed. The overall use and the use of the three perch types were investigated in order to assess the use of the perch types and an effect of the location of the perch in the housing system of four enriched colony housing systems which are used in practice.

\section{Materials and Methods}

\section{Animals}

This study was performed in the course of a joint research project to refine and optimize the enriched colony housing system for laying hens. Hens of the layer line Lohmann Selected Leghorn (LSL) and Lohmann Brown (LB) were housed in four different enriched colony housing systems (system A=Big Dutchman, Type KV 1500 a-D40; system $\mathrm{B}=$ SALMET International $\mathrm{GmbH}$, Type 4000/735; system $\mathrm{C}=$ SALMET International GmbH, Type FC-S 715/725; system D=TESO Ten Elsen GmbH \& Co. KG, Type 206-740). System A and B were stationed in one barn at the Institute for Poultry education and applied research in Kitzingen, Germany. The systems C and D were located in two separate barns at the Ludwig-Maximilians-University in Munich, Germany. The hens of all four systems hatched on the $24^{\text {th }}$ of June 2010 , were not beak trimmed and reared in cage systems at the Kommanditgesellschaft Geflügelzuchtbetriebe Gudendorf-Ankum, GmbH Co, Ankum, Germany. On the $27^{\text {th }}$ of October, at the age of $17 \mathrm{wk}$ and $6 \mathrm{~d}$, the hens were randomly housed in the four enriched colony housing systems A to D with alternating filling of the layer lines (LSL and LB) in the cage units. The systems differed particularly in size and alignment of the functional areas nest, dust bath, and perches (Figure 1). In system A, 40 hens per cage (stocking density: $800 \mathrm{~cm}^{2} /$ hen, 720 hens in total, 360 of each layer line) were housed with two low perches (L1, L2; $10 \mathrm{~cm}$ distance to cage floor) on the side of the cage unit, one low perch (L3; $8 \mathrm{~cm}$ distance to cage floor) in the middle underneath the drinking trough and two high perches $(\mathrm{H} 1, \mathrm{H} 2 ; 30 \mathrm{~cm}$ distance to cage floor) between each side perch and the middle perch. A total of 18 cages, stacked in two levels were stationed in one barn together with the system B. In system B, 33 hens were housed per cage (stocking density: $800 \mathrm{~cm}^{2} /$ hen, 792 hens in total, 396 of each layer line) with four low perches (L1, L2, L3, L4; 8-16 cm distance to cage floor) and one high perch ( $\mathrm{L} 1 ; 30 \mathrm{~cm}$ distance to cage floor). In total, 24 cages of the system B were stacked in two levels and two rows. In system C, 50 hens were housed per cage (stocking density: $880 \mathrm{~cm}^{2} /$ hen, 300 hens in total, 150 of each layer line) with four low perches (L1, L2, L3, L4; 13-18 cm distance to cage floor) and two high perches (H1, H2; $27 \mathrm{~cm}$ distance to cage floor). Six cages of the system $\mathrm{C}$ were stacked in three levels. All perches in systems A, B and C were made of galvanized metal. In system D, 40 hens were housed per cage (stocking density: $800 \mathrm{~cm}^{2} /$ hen, 480 hens in total, 240 of each layer line) with two low plastic perches (L1, $7 \mathrm{~cm}$ distance to cage floor; $\mathrm{L} 2,9 \mathrm{~cm}$ distance to cage floor) in the middle of the cage underneath the drinking trough and one high perch of galvanized metal $(\mathrm{H} 1,25 \mathrm{~cm}$ distance to cage floor). The system $\mathrm{D}$ was constructed of two rows of cages on two levels with three cages in each row. In all of the observed systems, only
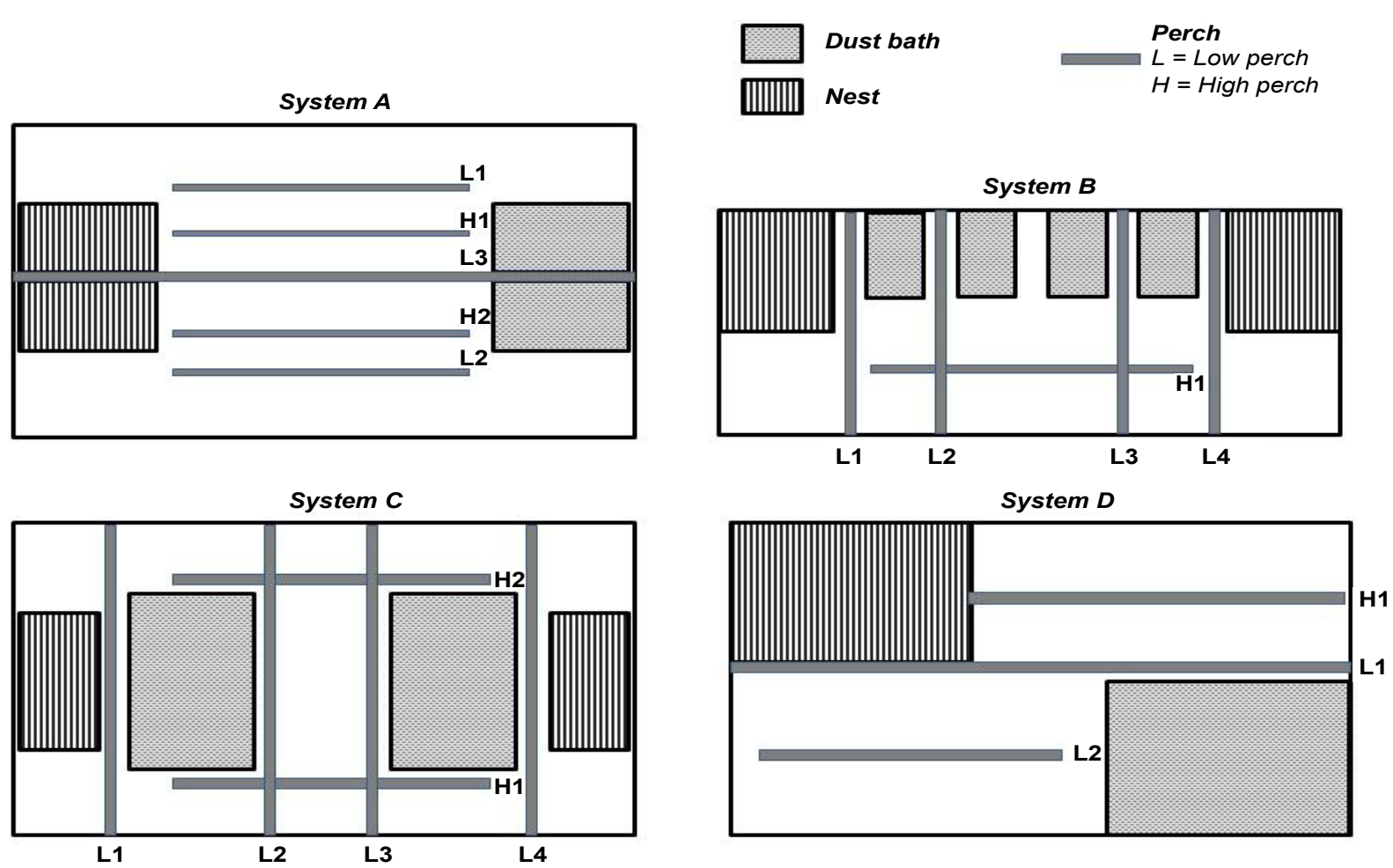

Figure 1: Functional areas dust bath, nest and perches in the four observed enriched colony housing systems $A$ to $D$ considering high and low perches. The presentation is not to scale. 
artificial lighting was used with a $14 \mathrm{~h}$ daylight period (4 AM-6 PM). The hens were fed with conventional layer feed of three phases during the laying period (Korngold LAM $41^{\circ}$ from $18^{\text {th }}$ until $47^{\text {th }}$ week of age, Korngold LAM $40^{\circ}$ from $48^{\text {th }}$ until $63^{\text {rd }}$ week of age, and Korngold LAM $38^{\circ}$ from $64^{\text {th }}$ until $70^{\text {th }}$ week of age; BayWa AG, Bockhorn, Germany). The management of the farms was consistent to ensure randomization.

\section{Behavior observations}

For behavior observations, video recordings with infrared cameras of the type VTC-E220IRP with IR-LED (Santec Security Solutions/ Sanyo Video AG, Ahrensburg, Germany) were taken for 48 hours during three observation periods (OPs) within the laying period (first OP: 24-25 weeks of age; second OP: 47-48 weeks of age; third OP: 63-64 weeks of age). By this, the observation periods were evenly distributed throughout the laying period. Because of technical reasons, only hens of the strain Lohmann Selected Leghorn were observed. The video signals of the cameras were transferred to encoder boxes (Indigo Vision 8000, Indigo Vision, Inc., Edinburgh, UK). Network cables connected the encoder boxes with Switchports (AT-FS 708 Switch, Allied Telesis, Inc., USA), that were connected to a computer. The software used was Indigo Vision Control Center (Version 3.16.09, Indigo Vision, Inc., Edinburgh, UK).

In systems A (33 hens per unit) and B (40 hens per unit) four randomly chosen cage units, in system $C$ three randomly chosen cage units ( 50 hens per unit) and in system $\mathrm{D}$ (40 hens per unit) six randomly chosen cage units were observed by video recordings (three cage units in the third observation period in system D). The scan sampling method by Martin and Bateson [22] was used to determine the use of the perches and prevalence of hens on specific perches. Using this method, a group of hens is observed at time points determined prior to the observation in order to assess the use of the functional area perch. The first time point determined in this study was 30 minutes after the beginning of the daytime and then a sampling followed hourly during the day and twice within the night. Thereby, the absolute number of hens on the different perches was counted in hourly intervals at daytime (4:30 AM to 5:30 PM) and twice at nighttime (8:30 PM and 1:30 AM). For the overall use of perches, the total number of hens standing or sitting with both legs on any perch was related to the total number of hens in the cage.

\section{Statistical analyses}

The determined frequency of perch use was presented as percentage of the number of hens per meter perch per unit. A Chi-Square-Test was used to analyze the differences between the four different housing systems at day and nighttime as well as between the different observation periods (Excel Tool by ACOMED Statistics, Leipzig, Germany) [23]. The absolute numbers of hens on different perches and at different times of the day was documented. To analyze the frequency of hens on the perch types, grouped into three categories (low, low underneath the drinking trough and high), the number of hens on one meter of a specific perch was related to the total number of hens in the particular unit (system $\mathrm{A}$ $\mathrm{n}=4$ units; system $B \mathrm{n}=4$ units, system $C \mathrm{n}=3$ units, system $\mathrm{D} n=6$ units, last $\mathrm{OP} n=3$ units). The frequency of hens on the different perch types was calculated as arithmetic means of the perch use during the day and night time in the observed units ( 14 observations times during the day, two at night). A t-test was used to calculate significant differences in the frequency of hens on the different perch types as well as the different housing systems. A correction for multiple testing was performed according the Bonferroni and Holm-method. The statistical level was set at $P<0.05$. Additionally a Cohen $\mathrm{d}$ was calculated to quantify the effect of different housing systems and perch types. Cohen [24] refers to a small, medium and large effect if $d$ is $0.2,0.5$ or 0.8 respectively.

\section{Results}

At daytime, an average of $23.9 \%$ of the laying hens used the perches in the enriched colony housing systems (Table 1). The average perch use at daytime varied, and ranged from the lowest usage of $17.4 \%$ in system A to the highest use of $29.9 \%$ in system B. In the first (24-25 weeks of age) and third (63-64 weeks of age) observation periods, there were no significant differences between the four different systems $(P>0.05)$. In the second (47-48 weeks of age) observation period, the perches in system A were used significantly less than those in system $\mathrm{D}(P \leq 0.05)$.

At nighttime, the hens showed a more frequent use of perches with an average of $62.1 \%$ (Table 1). The range of the average use was between $53.2 \%$ (first observation period, system $\mathrm{C}$ ) and $71.6 \%$ (third observation period, system A).

In system A, five perches were installed in the housing system, two low perches at the sides, one low perch in the middle (underneath the drinking trough) and two high perches between the low ones (Figures 1). A difference in the use of these perches was observed particularly during the daytime (Figure 3). At daytime, the low perch in the middle underneath the drinking trough was used more often than the low $(P$ $\leq 0.001, \mathrm{~d}=7.61)$ and the high perches in this housing system $(P \leq 0.01$, $\mathrm{d}=4.54)$. Even though the low perches were used less than the high perches during the daytime of all OPs, this was only significant in the third OP $(P=0.028, \mathrm{~d}=3.91)$.

In system $\mathrm{B}$, there was no notable effect of the perch height on the use of the perches at day- or nighttime in all observation periods (Figures 2 and 3 ).

At daytime (Figure 3), even though there was an effect of the perch height on the use of the perches visible in the system $C$, this was not significant in any of the observation periods $(P>0.05$, OP $1 \mathrm{~d}=3.23$, OP 2 $\mathrm{d}=2.77$, OP $3 \mathrm{~d}=3.09$ ). At nighttime in the second and third observation periods (Figure 2), the high perches were used more often than the low perches (OP $2 P=0.005, \mathrm{~d}=13.11$; OP $3 P=0.019, \mathrm{~d}=7.21$ ).

\begin{tabular}{|c|c|c|c|}
\hline & OP & $\begin{array}{l}\text { Layer on perch }(\%) \text { during } \\
\text { Night time (min/max) }\end{array}$ & $\begin{array}{l}\text { Layer on perch }(\%) \text { during } \\
\text { Daytime }(\min / \max )\end{array}$ \\
\hline \multirow{4}{*}{ System A } & 1 & $55.8(51.3 / 58.8)$ & $17.8(10.0 / 31.3)$ \\
\hline & 2 & $60.8(47.5 / 71.8)$ & $17.4(7.5 / 30.8)$ \\
\hline & 3 & $71.8(65.0 / 80.3)$ & $25.6(10.0 / 55.0)$ \\
\hline & Average & $62.8(47.5 / 80.3)$ & $20.3(7.5 / 55.0)$ \\
\hline \multirow{4}{*}{ System B } & 1 & $69.9(59.1 / 78.8)$ & $26.4(13.6 / 39.4)$ \\
\hline & 2 & $59.9(40.9 / 75.0)$ & $26.0(13.6 / 40.6)$ \\
\hline & 3 & $59.4(48.5 / 72.6)$ & $29.9(16.7 / 46.8)$ \\
\hline & Average & $63.1(40.9 / 78.8)$ & $27.4(13.6 / 46.8)$ \\
\hline \multirow{4}{*}{ System C } & 1 & $53.2(38.0 / 68.0)$ & $19.1(6.0 / 36.0)$ \\
\hline & 2 & $63.2(56.0 / 69.0)$ & $21.3(5.2 / 39.0)$ \\
\hline & 3 & $64.9(58.0 / 72.9)$ & $24.0(7.1 / 36.7)$ \\
\hline & Average & $60.4(38.0 / 72.9)$ & $21.5(5.2 / 39.0)$ \\
\hline \multirow{4}{*}{ System D } & 1 & $66.2(42.5 / 86.3)$ & $24.7(2.5 / 41.3)$ \\
\hline & 2 & $54.0(40.9 / 64.1)$ & $29.7(7.4 / 51.5)$ \\
\hline & 3 & $66.1(51.3 / 74.3)$ & $29.2(13.2 / 51.5)$ \\
\hline & Average & $62.1(40.9 / 86.3)$ & $27.9(2.5 / 51.5)$ \\
\hline
\end{tabular}

Table 1: Average percentage (\%), minimum and maximum of laying hens per meter perch in systems $A$ to $D$ at night time and day time in the three observation periods. OP=Observation Period (1=First observation period, 24-25 weeks of age $2=$ Second observation period, 47-48 weeks of age; $3=$ Third observation period, 63-64 weeks of age). 


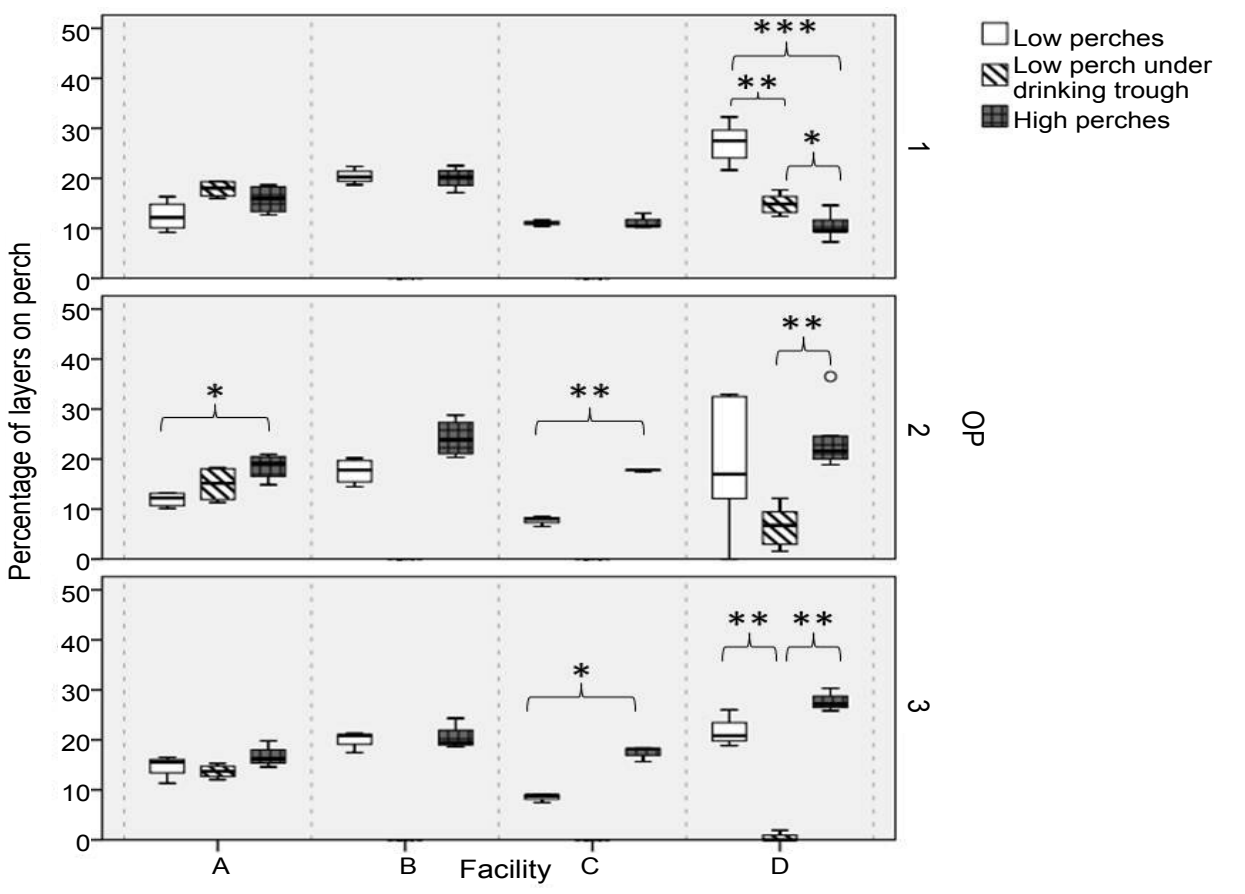

Figure 2: Average percentage (\%) of layers per meter of the three perch types low, low under the drinking trough and high, in systems $A$ to $D$ at night time in the three observation periods. OP=Observation period ( $1=$ first observation period, $24-25$ weeks of age; $2=$ Second observation period, $47-48$ weeks of age; $3=$ Third observation period, 63-64 weeks of age). ": $p$-value $<0.05,{ }^{, *}:$-value $<0.01,{ }^{* * *}: p$-value $<0.001$.

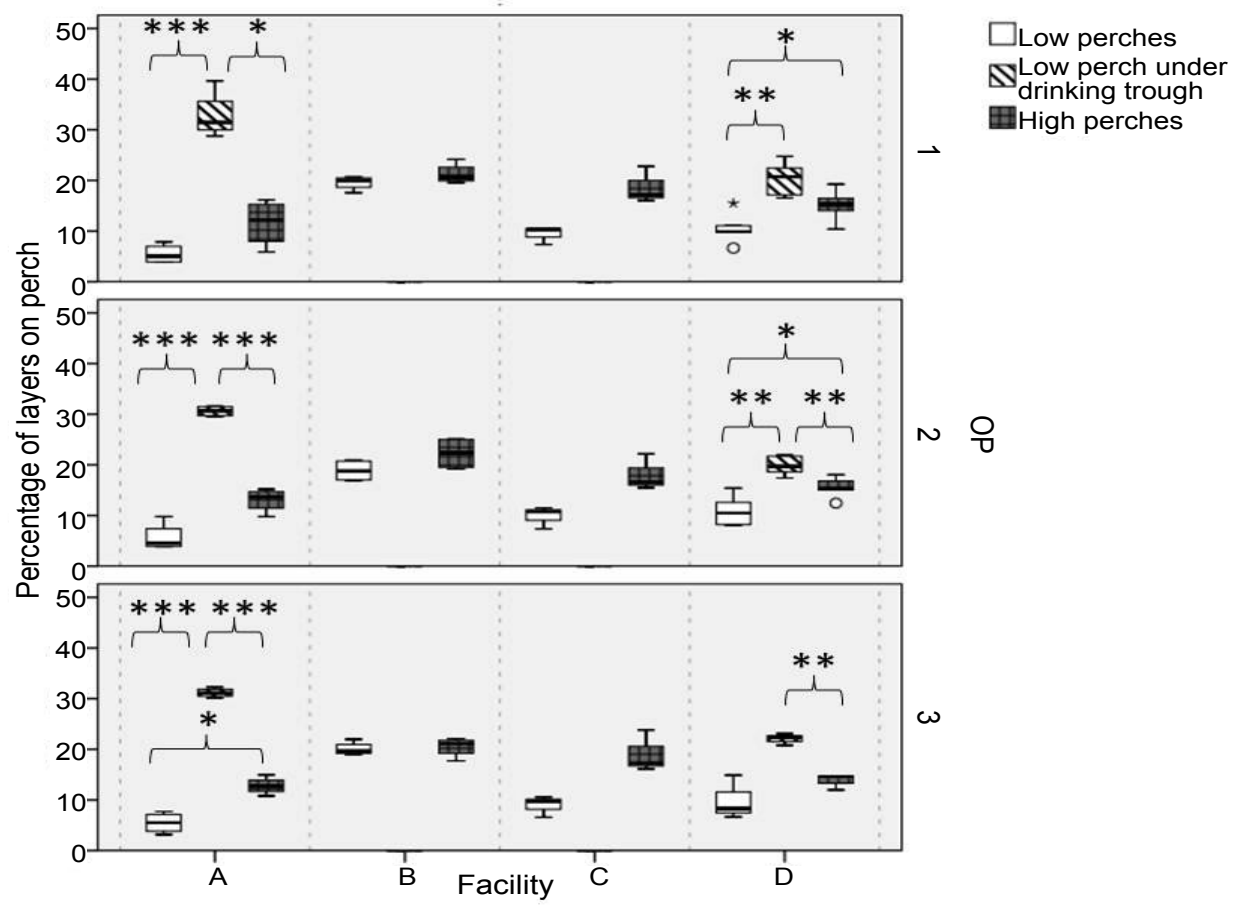

Figure 3: Average percentage (\%) of layers per meter of the three perch types low, low under the drinking trough and high, in systems $A$ to $D$ at daytime in the three observation periods. OP=Observation period ( $1=$ first observation period, $24-25$ weeks of age; $2=$ Second observation period, $47-48$ weeks of age; $3=$ Third observation period, 63-64 weeks of age). ": $p$-value $<0.05,{ }^{* *}:$-value $<0.01,{ }^{, * *}:$-value $<0.001$.

In system D (Figure 3), the low perch in the middle of the system underneath the drinking trough was used more often than all other perches at daytime in all observation periods. The frequent use of this perch was especially determined by hens that used the perch to reach the drinking trough. The high perch was used more frequently at daytime in all observation periods compared with the low perch located at the side of the system (OP $1 P=0.046, \mathrm{~d}=1.62$; OP $2 P=0.049$, $\mathrm{d}=1.82$ ). The prevalence of hens on specific perches at nighttime in 
system D changed from the first to the third observation period (Figure 2 ). In the first observation period, the low perch in the middle of the system underneath the drinking trough and the low perch were used $(P<0.05)$ more frequently than the high perch. In the second and third observation periods, the low perch in the middle of the system underneath the drinking trough was used less than the low and high perch.

\section{Discussion and Conclusions}

In the four enriched colony housing systems tested in our study, an average of $23.9 \%$ of the hens were observed sitting or standing on the perches at daytime. The observed average use of perches, ranging from 17.4 to $29.7 \%$, differed between housing systems and observation periods, we suggest that this was caused because the number of hens on perches was influenced by the number of hens in other functional areas (food trough, dust bath, nest) showing other behavior than resting.

An average of $62.1 \%$ of the hens in this study used the perches at nighttime. The average ranged between 53.2 and $71.6 \%$. Thus, 28.4 to $46.8 \%$ of the hens in the observed enriched colony housing systems did not use the perches during the night. Other authors reported a high variability in the use of perches, with 60 to $99 \%$ of laying hens resting on perches in furnished cage systems at nighttime [4,14,18]. Telle [17] observed only 26 to $67 \%$ laying hens on a perch at nighttime. The fact that not all of the hens in this study used a perch at night could be explained by the preference of hens for specific perches, causing an "overcrowding" on specific perches and thus insufficient space for all of the hens on these perches. Similar observations were done by authors analyzing behavior of laying hens in an aviary systems, in which by laying hens preferred perches were overcrowded and others in the same housing system in contrast not used by the hens [25]. Since 28.4 to $46.8 \%$ of the hens did not use a perch at night, even though hens are highly motivated to perch [26], it should be discussed, if the provided perch space of $15 \mathrm{~cm}$ per hen is sufficient or if more space, especially on high perches, should be provided.

Analysis of the usage of individual perch types at daytime showed that not only the height but also the location of the perch had an effect. If provided, low perches underneath the drinking trough in the middle of the housing systems (systems A and D) were used by the highest proportion of hens. Similarly, Duncan et al. [4] observed that perches near drinking troughs or feeding areas were used frequently at daytime. Perches are installed to provide hens with an area for resting. However, if hens can use them to reach a water resource, the increased movement on and near these perches can deplete their original function as rest areas.

Other low perches in the systems that were not installed underneath the drinking trough were less commonly used than the high perches at daytime. These observations are to some extent in contrast to those described by other authors. Blokhuis [27] observed a frequent use of low perches at daytime, especially for short naps and grooming behavior. Rönchen et al. [16] and Hergt [18] reported a more frequent use of low perches than high perches at daytime in enriched colony housing systems. Rönchen et al. [16] explained the lesser use of high perches by the inappropriate design, the position in the cage system and the insufficient distance to the ceiling of the cage. In this study, low perches were used more than high perches at daytime only if they were installed underneath a drinking trough. The use of and the preference for high perches was interpreted as an anti-predator behavior by several authors $[11,28]$. Also, Struelens and Tuyttens [7] observed a more frequent use of high perches if the distance to the ceiling of the cage was at least 19 to $24 \mathrm{~cm}$. The high perches in this study all had a minimum distance of $29 \mathrm{~cm}$ to the ceiling.

At nighttime, the use of perches differed in the different housing systems and the observation periods. In system A, the differences were only marginal and a systematic prevalence of hens on specific perches was not visible at nighttime. In system $B$, no differences in terms of frequency in the use of specific perches could be observed, neither at daytime nor at nighttime. In system $\mathrm{C}$ in the second and third observation period, more hens were observed on the high perches compared to the low perches during the night observation. These results agree with findings of Schrader and Müller [11] and Struelens and Tuyttens [7] who observed that the height of perches influenced their use and that hens preferred to rest on high perches. In system D, the prevalence of hens on specific perches at nighttime changed from the first to the third observation period, which is, with progressing laying period and age of the hens. The low perch in the middle of the system underneath the drinking trough that was used frequently at the beginning of the laying period was avoided in the third observation period, when more hens were observed on the high perch. We conclude that the hens first had to learn to hold on to the relatively slippery, round high perch which was made of galvanized metal in contrast to the low perch in this system made of plastic. A systematic comparison of the housing systems $\mathrm{A}$ to $\mathrm{D}$ is not feasible, because of differences in the number of hens per cage and available perch types in the cages. This is due to the reason, this study was conducted to assess the use of perches in enriched colony housing systems under conditions used in practice.

In this study, the number of hens using a specific perch type was applied as a measure to assess the use of perches. Pickel et al. [10] recommended considering the quality of rest (balance movements) as an additional important factor. By applying this method, it should be possible to explain why the hens did not use the high perch in system $\mathrm{D}$ at the beginning of the laying period. Furthermore, the hens in our study had been raised in a conventional cage system without any access to perches, which is another factor that might influence the later use of perches. As shown by Heikkilä et al. [29], it seems to be important that laying hens have early access to perches, as hens used these more often once they were older if they had learned the use at a younger age. However, in this study we aimed to observe hens as they are housed in practice and the pullets for cage systems in practice are raised without perches.

In conclusion, the results showed that laying hens in enriched colony housing systems used the provided perches. However, a fraction of the hens (28.4 to $46.8 \%$ ) did not use the perches at night time; we suggest that this was observed because they preferred specific perches and areas of the cages, which were already occupied by other hens. The use of the perches varied, depending on the daytime as well as the type of the perch (low, low underneath the drinking trough, high). There was a high frequency of hens on high perches in the observed housing systems, not only at nighttime but under specific circumstances also at daytime. Perches installed underneath the drinking troughs were used frequently at daytime. It should be considered that the hens used these perches not to rest but rather to have better access to the drinking trough. Since the perches of all systems were used and a system-related influence in the overall use was not observed, it seems that the use of perches is a basic need and as observed by other authors, hens show a high motivation to perch at night [26]. It has been shown by other authors that perches allow the hens to show species-specificresting behavior [4,5]. Considering the results of this study, it can be recommended that a sufficient number of high perches should be 
Citation: Louton H, Rauch E, Reese S, Erhard M, Bergmann S (2016) Effect of Perch Height and Position on the Usage in Enriched Colony Housing Systems for Laying Hens. J Vet Sci Technol 7: 339. doi:10.4172/2157-7579.1000339

offered, so that all hens have access to these obviously preferred perches. It should be considered if additional perch space should be offered if perches are installed underneath the drinking trough and it should be reconsidered if the required perch space of $15 \mathrm{~cm}$ per hen is sufficient.

\section{Acknowledgements}

This project was supported by funds of the Federal Ministry of Food and Agriculture (BMEL) based on a decision of the Parliament of the Federal Republic of Germany via the Federal Office for Agriculture and Food (BLE, Grant number 2813600507) under the innovation support program.

\section{References}

1. Destatis (2015) Statistisches Bundesamt. Fachserie 3, Reihe 4.2.3.

2. https://www.bigdutchman.com/en/nc/poultry-production/news/dictionary/ dchar/g/term/standing-heat.html

3. https://www.bundesverfassungsgericht.de/SharedDocs/Entscheidungen/ DE/2010/10/fs20101012 2bvf000107.htm

4. Duncan ET, Appleby MC, Hughes B (1992) Effect of perches in laying cages on welfare and production of hens. Br Poult Sci 33: 25-35

5. Olsson IA, Keeling LJ (2000) Night-time roosting in laying hens and the effect of thwarting access to perches. Appl Anim Behav Sci 68: 243-256.

6. Muiruri HK, Harrison PC, Gonyou HW (1990) Preferences of hens for shape and size of roosts. Appl Anim Behav Sci 27: 141-147.

7. Struelens E, Tuyttens FAM (2009) Effects of perch design on behaviour and health of laying hens. Animal Welfare 18: 533-538.

8. Scott GB, MacAngus G (2004) The ability of laying hens to negotiate perches of different materials with clean or dirty surfaces. Animal Welfare 13: 361-365.

9. Struelens E, Tuyttens FA, Duchateau L, Leroy T, Cox M, et al. (2008) Perching behaviour and perch height preference of laying hens in furnished cages varying in height. Br Poult Sci 49: 381-389.

10. Pickel T, Scholz B, Schrader L (2010) Perch material and diameter affects particular perching behaviours in laying hens. Appl Anim Behav Sci 127: 37-42.

11. Schrader L, Müller B (2009) Night-time roosting in the domestic fowl: the height matters. Appl Anim Behav Sci 121: 179-183.

12. Faure JM, Jones RB (1982) Effects of sex, strain and type of perch on perching behaviour in the domestic fowl. Applied Animal Ethology 8: 281-293.

13. Chen DH, Bao J, Meng FY, Wei CB (2014) Choice of perch characteristics by laying hens in cages with different group size and perching behaviours. Appl Anim Behav Sci 150: 37-43.
14. Appleby MC, Smith SF, Hughes BO (1993) Nesting, dust bathing and perching by laying hens in cages: effects of design on behaviour and welfare. $\mathrm{Br}$ Poult Sci 34: 835-847.

15. Abrahamsson P, Tauson R, Appleby MC (1996) Behaviour, health and integument of four hybrids of laying hens in modified and conventional cages. Br Poult Sci 37: 521-540

16. Rönchen S, Scholz B, Hamann H, Distl O (2010) Use of functional areas, perch acceptance and selected behavioural traits in three different layer strains kept in furnished cages, small group systems and modified small group systems with elevated perches. Eur Poult Sci 74: 256-264.

17. Telle M (2011) Verhaltensbeobachtungen bei der Kleingruppenhaltung von Legehennen (LSL). Dissertation, Dr. Med. Vet., Ludwig-Maximilians Universität München, Munich, Germany.

18. Hergt $F$ (2007) Vergleichende Untersuchung zum Verhalten von Legehennen in Klein- und Großvolierenhaltung. Dissertation, Dr. Med. Vet., LudwigMaximilians-Universität München, Munich, Germany.

19. Carmichael NL, Walker AW, Hughes BO (1999) Laying hens in large flocks in a perchery system: influence of stocking density on location, use of resources and behaviour. Br Poult Sci 40: 165-176.

20. Appleby MC, Walker AW, Nicol CJ, Lindberg AC, Freire R, et al. (2002 Development of furnished cages for laying hens. Br Poult Sci 43: 489-500.

21. Plattner C (2016) Behaviour of non-beak-trimmed laying hens in alternative housing systems with a special focus on the pecking behaviour. Dissertation, LMU München: Faculty of Veterinary Medicine, Munich, Germany.

22. Martin P, Bateson P (2007) Measuring Behaviour, an Introductory Guide Cambridge University Press, Cambridge, UK.

23. Acomed (2013) Chi-Quadrat-Test (Vierfelder-Tafel).

24. Parker RI, Hagan-Burke S (2007) Useful effect size interpretations for single case research. Behav Ther 38: 95-105.

25. Campbell DL, Makagon MM, Swanson JC, Siegford JM (2016) Perch use by laying hens in a commercial aviary. Poult Sci.

26. Olsson IAS, Keeling IJ (2002) The Push-Door for Measuring Motivation in Hens: Laying Hens are Motivated to Perch at Night. Animal Welfare 11: 11-19.

27. Blokhuis HJ (1984) Rest in poultry. Appl Anim Behav Sci 12: 289-303.

28. Newberry RC, Estevez I, Keeling LJ (2001) Group size and perching behaviour in young domestic fowl. Appl Anim Behav Sci 73: 117-129.

29. Heikkilä M, Wichman A, Gunnarsson S, Valros A (2006) Development of perching behaviour in chicks reared in enriched environment. Appl Anim Behav Sci 99: 145-156 